\title{
Acoustic identification of five insectivorous bats by their echolocation calls in the Sahelian zone of Far North Cameroon
}

\author{
Eric Moise Bakwo Fils ${ }^{1 *}$, Aaron Manga Mongombe ${ }^{1}$, David Emery Tsala ${ }^{1}$ and Joseph Lebel Tamesse ${ }^{2}$
}

\begin{abstract}
Background: Despite their abundance and ecological importance, bats are under significant threat worldwide. There is little information about their distribution, roosting, and habitat requirement for most species, making assessing which species is threatened or in need of special conservation measures difficult. The knowledge gap may partly be due to limitations of the old methods of studying bats which mainly involved capture/or observational techniques.
\end{abstract}

Material and methods: In order to evaluate the potential of identifying insectivorous bats by their echolocation calls in the Sahelian zone of northern Cameroon, 65 bats belonging to five species were captured using standard mist netting: Mops condylurus, Chaerephon major, Mops niveiventer, Scotophilus dinganii, and Scotophilus leucogaster. The bats were identified by using morphometric measurements. An Anabat SD1 detector was later used to record echolocation calls of each individual bat in flight after it was hand-released. The sonogram of each individual bat was analyzed using Analook and categorized into two call types (frequency modulation and frequency modulation/ quasi constant frequency) in order to develop a library of bat reference calls that could be used for a qualitative acoustic survey and species identification. Discriminant function analysis (DFA) was applied to search phase calls of the 65 individual bats in order to evaluate the potential for classifying calls into five species groups. Seven parameters calculated from each search phase call were used to classify calls.

Results: Bats where place into two groups according to the structure of calls: FM bats (Mops condylurus, Chaerephon major, Mops niveiventer) and FM/QCF bats (Scotophilus dinganii and Scotophilus leucogaster). The DFA resulted in a correct overall classification of $69.7 \%$.

Conclusion: This preliminary study showed that DFA of call parameters is a feasible method that can be used to identify insectivorous bats in the region by their echolocation calls.

Keywords: Echolocation, Maroua, Bats, Cameroon, Anabat SD1 detector, Sonogram

\section{Background}

Bats (Order Chiroptera) have their greatest diversity in the tropics (Willig, Kaufman, \& Stevens, 2003). They provide key ecosystem services such as plant pollination, seed dispersal, insect population regulation (Kalka, Smith, \& Kalko, 2008; Kunz, Torrez, Bauer, Lobova, \& Fleming, 2011; Lobova, Geiselman, \& Mori, 2009) and serve as excellent bioindicator taxa for monitoring environmental

\footnotetext{
*Correspondence: filsbkw27@gmail.com

'Department of Biological Sciences, Faculty of Sciences, University of Maroua, Maroua, Cameroon

Full list of author information is available at the end of the article
}

health (Jones, Jacobs, Kunz, Willig, \& Racey, 2009; Medellin, Equihua, \& Amin, 2000; Ochoa 2000). Yet, despite their importance, many populations of bat species are declining worldwide (Mickleburgh, Hutson, \& Racey, 1992; Racey, 1998). Schipper et al. (2008) pointed out that globally, a quarter of all bat species are considered threatened mainly as a consequence of extensive habitat loss and roost disturbance. One of the greatest and least appreciated threats to bats is the lack of basic information about many species (Mickleburgh et al., 1992). Indeed, very little information is known about species requirement and distribution (Hutson, Mickleburgh, \& Racey, 2001); 
this in turn makes assessing which species is in need of immediate conservation measures difficult.

In Cameroon, bats are rarely considered in biodiversity conservation plans mainly because of the lack of basic information on their distribution, ecology, and behavior.

Such information about bats in Cameroon still remains limited in spite of major recent contributions by Bakwo Fils (2009, 2010a, 2010b, 2014), Bakwo Fils, Bol, and Tchuenguem Fohouo (2012), Bakwo Fils et al. (2014), Bol, Guieké, and Tsala (2011), Cosson (1995); Hassanin (2014), Lebreton, Bakwo Fils, Takuo, and Diffo (2014) and Sedlàcek, Horak, Riegert, Reif, and Horàcek (2006), which led to the detection of species new to the country. Despite these contributions, much is still to be known concerning bat habitat and feeding ecology. Moreover, all the available data is based on traditional capture methods of surveying bats (e.g., mist nets and harp traps). O'Farrell (1997, p. 1), pointed out that "not all bat species and not all individuals within a species are susceptible to capture."

Acoustic surveys using bat detectors are increasingly being used in addition to these traditional methods (Jones et al., 2009; O’Farrell \& Miller, 1999; Ochoa, O'Farrell, \& Miller, 2000). According to O'Farrell (1997), acoustic detection has been shown to be a powerful supplement to standard capture methods to identify many insectivorous bats that are underrepresented in field inventories. Indeed, bats of the families Rhinolophidae, Hipposideridae, and some subfamilies of Vespertilionidae are very skilled at avoiding mist nets because of their high versatility inflight and efficient echolocation calls (Kingston, Francis, Akbar, \& Kunz, 2003). Acoustic detection depends on the use of ultrasonic bat detectors to monitor echolocation calls produced by insectivorous bats. These detectors are widely used to study habitat use by bats (Krusic, Yamasaki, Neefus, \& Pekins, 1996; Law, Anderson, \& Chidel, 1999; Vaughan, Jones, \& Harris, 1997). Detectors often reveal the presence of more species at a site than capture techniques (Kuenzi \& Morrison, 1998; Murray, Britzke, Hadley, \& Robbins, 1999; O'Farrell \& Gannon, 1999) and can be deployed in a much wider variety of locations than capture techniques (O'Farrell, Miller, \& Gannon, 1999). Bat detectors can also be used to accurately identify bat (Britzke, Murray, Heywood, \& Robbins, 2002; O'Farrell et al., 1999; Parsons \& Jones, 2000). Detectors, unlike netting and trapping, do not involve handling and thus minimize disturbance. However, before acoustic methods can be used for inventories, a library of authenticated calls is required to describe the echolocation call characteristics of each species present in a particular area so that, when calls of unknown bats are recorded in the field, they can be compared with these reference calls. Acoustic survey has never been used to characterize and identify echolocation calls of bats anywhere in Cameroon. This explains the total absence of echolocation reference call libraries.

The main purpose of this study was therefore to use the Anabat SDI detector, which is a frequency division detector, to record, identify, and describe the calls of the most abundant insectivorous bats of Sahelian zone of northern Cameroon, notably Mops condylurus, Chaerephon major, Mops niveiventer, Scotophilus dinganii, and Scotophilus leucogaster (Bol et al., 2011) and also to evaluate the potential for acoustic identification by discriminant function analysis (DFA) using restricted sample sizes. This preliminary study will provide the basis for future acoustic monitoring studies in the region and elsewhere in the country.

\section{Methods}

\section{Study site}

The study was conducted in the town of Maroua capital of the Far North Region of Cameroon. The town is situated in the Sudano-Sahelian zone of the country between latitudes $10^{\circ}$ and $13^{\circ}$ north and longitudes $13^{\circ}$ and $15^{\circ}$ east (Yengue \& Callot, 2002). The region has the Sudano-Sahelian (semi-arid) climate characterized by variations in climatic elements (Bourtrais et al., 1984). There are two alternating seasons: a long dry season that runs from October to May and a short rainy season from June to September. The mean annual rainfall is about $600-900 \mathrm{~mm}$ and mostly recorded in the months of July and August. The average temperature is about $28{ }^{\circ} \mathrm{C}$ but can attain a maximum of $45^{\circ} \mathrm{C}$ in the months of March and April (Yengue \& Callot, 2002).

\section{Mist netting and identifications of bat species}

Bats were sampled for 18 non-consecutive nights between July 2012 and January 2013. Eight capture sites comprising foraging, drinking, and roost sites were selected in the study area based on prior knowledge of bats activities (Table 1). The geographical positions of each site were noted using a hand-held GPS (Garmin eTrex). Free-flying bats were captured using two mist nets with four shelves $(9 \times 2.60 \mathrm{~m}, 16-\mathrm{mm}$ mesh size $)$ that were tied between 4-m-long poles. The nets were deployed from $6 \mathrm{pm}$ to about midnight. Each time a bat flew into the net, it was carefully untangled by an observer and identified to species level using morphometric measurements (Hayman \& Hill, 1971; Robbins, De Vree, \& Van Cakenberghe, 1985; Rosevear, 1965). After proper identification, the bats were released for validation of echolocation calls.

\section{Acoustic recording of echolocation calls}

Echolocation calls of 16 Chaerephon major, 12 Mops condylurus, 10 Mops niveiventer, 12 Scotophilus leucogaster, and 19 Scotophilus dinganii were recorded in flight using the Anabat SD 1 bat detector (Titley 
Table 1 Bat species recorded in eight survey areas in Maroua, Cameroon (numbers in parentheses refer to captured individuals)

\begin{tabular}{|c|c|c|c|c|c|c|c|c|}
\hline \multicolumn{9}{|c|}{ Number of individuals per site } \\
\hline Sites & A & $B$ & C & $\mathrm{D}$ & $E$ & $\mathrm{~F}$ & $G$ & $\mathrm{H}$ \\
\hline Altitude (m) & 404 & 402 & 403 & 420 & 401 & 403 & 403 & 414 \\
\hline Capture nights & 04 & 04 & 03 & 01 & 01 & 01 & 03 & 01 \\
\hline GPS coordinates & $\begin{array}{l}10^{\circ} 35^{\prime} 38.5^{\prime \prime} \mathrm{N} \\
14^{\circ} 20^{\prime} 15.2^{\prime} \mathrm{E}\end{array}$ & $\begin{array}{l}10^{\circ} 35^{\prime} 47.7^{\prime \prime} \mathrm{N} \\
14^{\circ} 18^{\prime} 54.1^{\prime \prime} \mathrm{E}\end{array}$ & $\begin{array}{l}10^{\circ} 35^{\prime} 90.2^{\prime \prime} \mathrm{N} \\
14^{\circ} 20^{\prime} 25.0^{\prime \prime} \mathrm{E}\end{array}$ & $\begin{array}{l}10^{\circ} 34^{\prime} 24.5^{\prime \prime} \mathrm{N} \\
14^{\circ} 16^{\prime} 54.6^{\prime \prime} \mathrm{E}\end{array}$ & $\begin{array}{l}10^{\circ} 35^{\prime} 39.8^{\prime \prime} \mathrm{N} \\
14^{\circ} 17^{\prime} 18.5^{\prime \prime} \mathrm{E}\end{array}$ & $\begin{array}{l}10^{\circ} 35^{\prime} 90.2^{\prime \prime} \mathrm{N} \\
14^{\circ} 20^{\prime} 25.0^{\prime \prime} \mathrm{E}\end{array}$ & $\begin{array}{l}10^{\circ} 35^{\prime} 58.8^{\prime \prime} \mathrm{N} \\
14^{\circ} 18^{\prime} 44.4^{\prime \prime} \mathrm{E}\end{array}$ & $\begin{array}{l}10^{\circ} 35^{\prime} 37.2^{\prime \prime} \mathrm{N} \\
14^{\circ} 17^{\prime} 19.5^{\prime \prime} \mathrm{E}\end{array}$ \\
\hline Habitat types & Drinking site & River bed & Drinking site & Roost site & Roost site & farmland & Drinking site & Roost site \\
\hline \multicolumn{9}{|l|}{ Molossidae } \\
\hline $\begin{array}{l}\text { Chaerephon } \\
\text { major }(n=23)\end{array}$ & - & - & 22 & 01 & - & - & - & - \\
\hline $\begin{array}{l}\text { Chaerephon } \\
\text { nigri }(n=01)\end{array}$ & - & 01 & - & - & - & - & - & - \\
\hline $\begin{array}{l}\text { Chaerephon } \\
\text { pumilus }(n=06)\end{array}$ & 01 & 02 & 01 & - & - & - & 02 & - \\
\hline $\begin{array}{l}\text { Mops condylurus } \\
(n=12)\end{array}$ & 01 & - & - & 11 & - & - & - & - \\
\hline $\begin{array}{l}\text { Mops niveiventer } \\
(n=10)\end{array}$ & - & - & - & 10 & - & - & - & - \\
\hline \multicolumn{9}{|l|}{ Vespertilionidae } \\
\hline $\begin{array}{l}\text { Nycticeinops schilieffenii } \\
(n=01)\end{array}$ & - & - & 01 & - & - & - & - & - \\
\hline $\begin{array}{l}\text { Pipistrellus } \\
\text { nanus }(n=01)\end{array}$ & - & - & - & - & - & 01 & - & - \\
\hline $\begin{array}{l}\text { Pipistrellus } \\
\text { nanulus }(n=01)\end{array}$ & - & 01 & - & - & - & - & - & - \\
\hline $\begin{array}{l}\text { Pipistrellus } \\
\text { inexpectatus } \\
(n=01)\end{array}$ & - & - & - & - & - & 01 & - & - \\
\hline $\begin{array}{l}\text { Scotoecus } \\
\text { hirundo }(n=02)\end{array}$ & & & 01 & - & - & - & 01 & - \\
\hline $\begin{array}{l}\text { Scotophilus } \\
\text { dinganii }(n=20)\end{array}$ & 05 & 12 & 03 & - & - & & 05 & \\
\hline $\begin{array}{l}\text { Scotophilus } \\
\text { leucogaster }(n=17)\end{array}$ & 10 & 03 & 03 & 01 & - & - & - & - \\
\hline \multicolumn{9}{|l|}{ Rhinolophidae } \\
\hline $\begin{array}{l}\text { Rhinolophus } \\
\text { fumigatus }(n=01)\end{array}$ & - & - & - & - & - & - & 01 & - \\
\hline Total individuals $(n=96)$ & 16 & 20 & 30 & 23 & 0 & 02 & 09 & 0 \\
\hline Total species $(n=13)$ & 03 & 06 & 06 & 04 & 0 & 01 & 04 & 0 \\
\hline
\end{tabular}

A: Pont vert; B: Pont rouge; C: Pont jaune; D: Pont Makabay; E: Collège de l'espoir; F: Mizao 1; G: Mizao; H: Pont palar. Including characteristic of different habitats investigated, altitude, and GPS coordinates

Electronics) after the bats were hand-released. All hand-releases and recordings were performed not far from where the bats were caught. The recordings were made with the detector held at the same height as the bat. The calls were recorded by an observer, who stood at about $20 \mathrm{~m}$ from the point of release. The detector was turned on as soon as the bat took off from the hands of the person releasing it. If possible, bats were followed on foot for some distance by the person holding the Anabat detector. The sensitivity of the detector was adjusted to the maximum sensitivity in order to record calls of very low intensity.

\section{Analysis of echolocation calls}

The structures of recorded call were analyzed using Analook software (version 4.8). One of the last echolocation calls in each sequence considered to be a search phase call and which allowed for selection of variables with confidence was selected (Betts, 1998). Calls were filtered before measurement using the "filter" command in Analook designed to exclude echoes and unwanted background noise. Additional cleaning was done using the "off dot" in Analook. This was done to ensure that selected variables could be measured with confidence. 
The following variables were measured from each selected sonogram by Analook: maximum frequency (Fmax), minimum frequency (Fmin), mean frequency (Fmean), frequency at the knee (Fk), time at knee (Tk), characteristic frequency $(\mathrm{Fc})$, time at characteristic frequency (Tc), duration (Dur), initial slope (Si), and characteristic slope $(\mathrm{Sc})$; frequency is given in kilohertz, time in millisecond, and slopes expressed in octave per second (octave/s). Based on the sonograms, bats were grouped into two call categories: frequency modulation types (FM) and frequency modulation followed by quasi constant frequency (FM/QCF). The discriminant function analysis was performed using seven variables as predictors of membership to five-bat species group (grouping variable). The predictors were Fmax, S1, Sc, Fmin, Fmean, Fc, and Tk. The variables Dur, Tk, and Tc failed the tolerance test and were not included in the analysis. The calls selected for classification were considered to belong to search phase.

\section{Statistical procedures}

For the five species form which calls were recorded, descriptive statistics were calculated for each bat species. Subsequently, a discriminant function analysis (DFA) was performed to assign echolocation calls to species (Russo \& Jones, 2002). The analysis determines which variables separate the species using discriminant functions (Digby \& Kempton, 1987). Eigenvalues indicate the strength of the functions in differentiating one group from another. Wilk's lambda values were obtained with a multivariate analysis of variance (MANOVA) to provide a measure of the relative discriminating power of each variable, the lower value, the higher, and the discriminating power of the variable (Rodríguez-San Pedro \& Simonetti, 2013). The significance level of lambda is determined from the distribution of chi-square (Parsons \& Jones, 2000). To obtain a graphical representation of the separation of groups based on their discriminant functions, we plotted the group centroids with 95\% confidence limits for separate functions and the canonical discriminant functions. For each species, descriptive statistics (mean $\pm \mathrm{SE}$ ) were calculated (Rodríguez-San Pedro \& Simonetti, 2013). All of these analyses were performed using the software SPSS 17.0.

\section{Results}

\section{Qualitative analysis of echolocation calls}

Eight sites were sampled within the Maroua area. Mist nets were monitored for 108 net hours and resulted in 96 captures of 13 species, representing seven genera in three families (Vespertilionidae, Molossidae, and Rhinolophidae). The predominant species were Chaerephon major $(n=23)$, Scotophilus dinganii $(n=20)$, and Scotophilus leucogaster $(n=17)$, Mops condylurus $(n=12)$, Mops niveiventer $(n=10)$ (Table 1$)$.

Species in which single or very few individuals were captured were not included in the DFA. This involved eight of the 13 captured species. The five bat species were Chaerephon major, Mops condylurus, Mops niveiventer, Scotophilus leucogaster, and Scotophilus dinganii. We analyzed a total of 172 call files from which the best quality calls were selected for further analysis. Descriptive statistics of calls from all species recorded are shown in Table 2. The echolocation call of Chaerephon major is a frequency modulation (FM) call, which is characterized by steep, linear pulses of highly variable frequencies and a slight leftward leaning (Fig. 1a). The call of Mops condylurus is a FM call. Pulses are steep and linear and leftward leaning (Fig. 1b). Echolocation call of Mops niveiventer is FM call and is made up of broadband, steep, near vertical pulses of variable frequencies (Fig. 1c). The echolocation call of Scotophilus dinganii is a FM/QCF call. The pulses are mostly broadband, curved with an initial steep FM sweep that ends with a QCF (Fig. 1d). The echolocation call of Scotophilus leucogaster is an FM/QCF call. Pulses are broadband,

Table 2 Descriptive statistics for echolocation parameters of five species of insectivorous bats in the Far North region of Cameroon

\begin{tabular}{|c|c|c|c|c|c|c|c|c|c|c|}
\hline Family/species & Call structure & $N$ & Fmax & Fmin & Fmean & $\mathrm{Fk}$ & $\mathrm{FC}$ & Duration & Tk & Tc \\
\hline \multicolumn{11}{|l|}{ Molossidae } \\
\hline Chaerephon major & FM & 16 & $39.3 \pm 6.9$ & $37.4 \pm 6.7$ & $36.4 \pm 6.7$ & $38.2 \pm 7.3$ & $33.7 \pm 7.3$ & $1.66 \pm 0.40$ & $0.35 \pm 0$ & $1.46 \pm 0.36$ \\
\hline Mops condylurus & FM & 12 & $37.8 \pm 3.8$ & $34.2 \pm 4.9$ & $36.4 \pm 4.5$ & $38.2 \pm 4.7$ & $33.67 \pm 5.1$ & $0.78 \pm 0.89$ & $0.003 \pm 0.1$ & $0.75 \pm 0.75$ \\
\hline Mops niveiventer & FM & 10 & $37.7 \pm 2.9$ & $34.1 \pm 2.6$ & $35.9 \pm 2.8$ & $37.6 \pm 2.7$ & $34.1 \pm 2.6$ & $0.74 \pm 0.10$ & $0.00 \pm 0.1$ & $0.71 \pm 0.65$ \\
\hline \multicolumn{11}{|l|}{ Vespertilionidae } \\
\hline Scotophilus dinganii & FM/QCF & 19 & $58.5 \pm 8.9$ & $52.6 \pm 6.2$ & $55.6 \pm 7.5$ & $58.5 \pm 8.9$ & $52.7 \pm 6.2$ & $0.88 \pm 0.92$ & $0.03 \pm 0.06$ & $0.86 \pm 0.84$ \\
\hline Scotophilus leucogaster & FM/QCF & 12 & $55.7 \pm 4.3$ & $50.6 \pm 3.0$ & $53.2 \pm 3.6$ & $55.7 \pm 4.3$ & $50.7 \pm 3.0$ & $0.81 \pm 0.23$ & $0.00 \pm 0.01$ & $0.80 \pm 0.21$ \\
\hline
\end{tabular}

The table shows mean \pm standard deviation and the range of the eight time and frequency parameters. Recordings were made with ANABAT bat detectors and analyzed with ANALOOK software. Initial slope of call (S1) and slope at the flattest section of the call (Sc) were delibrately excluded from the descriptive statistics. Frequency parameters were measured in kilohertz and time parameters in milliseconds (ms). Based on the sonograms, bats were grouped into two categories: frequency modulation types (FM) and frequency modulation followed by quasi constant frequency types (FM/QCF)

$N$ number of bats in sample, Fmax maximum frequency of the call, Fmin minimum frequency of the call, Fmean mean frequency of the call, $F_{K}$ frequency at the knee, $F_{C}$ characteristic frequency, Dur duration of the call, $T_{K}$ time into the call when $F_{K}$ is reached, and $T_{C}$ time into the call when $F_{C}$ is reached 


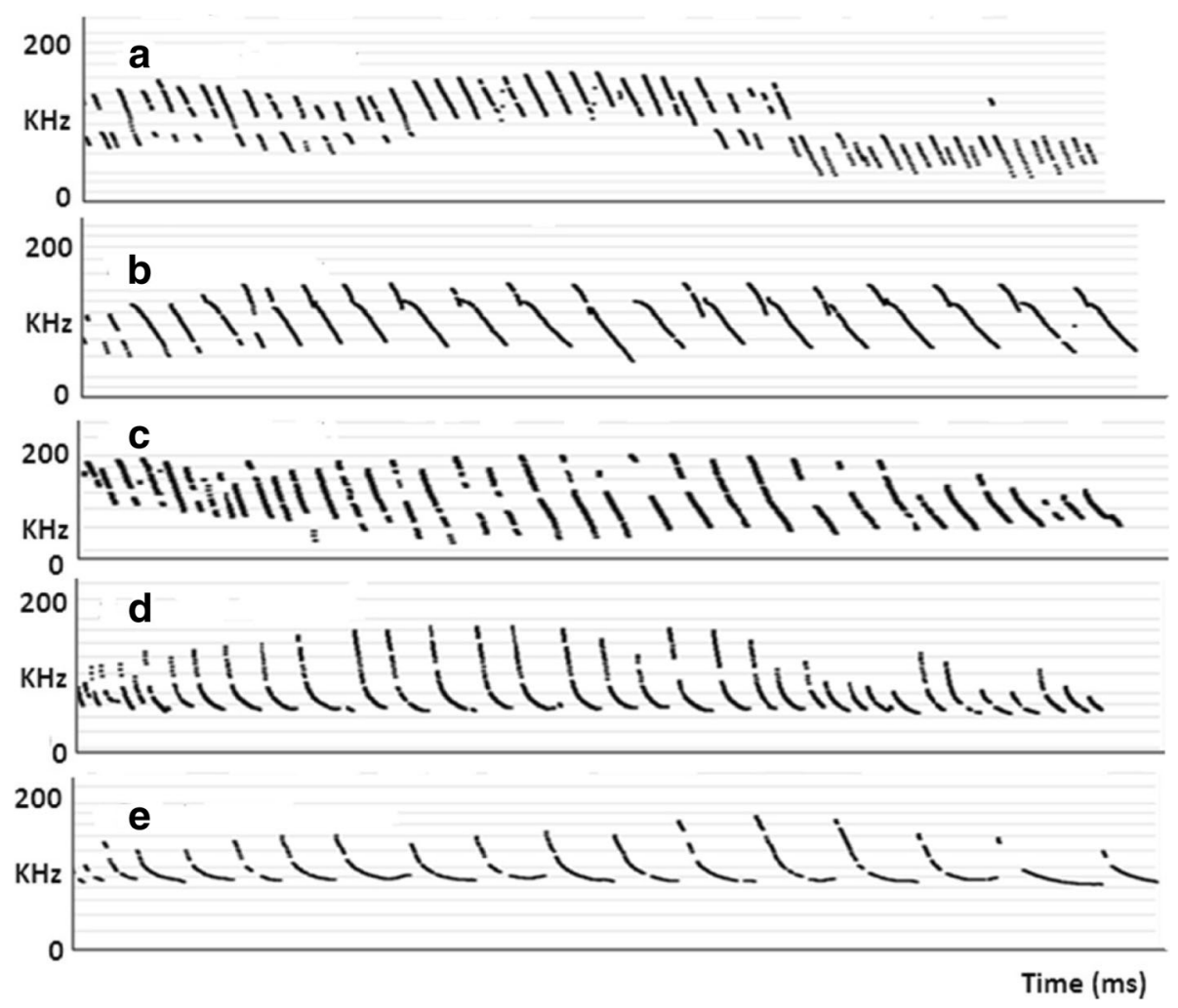

Fig. 1 Sonograms of echolocation calls of Chaerephon major (a), Mops condylurus (b), Mops niveiventer (c), Scotophilus dinganii (d), and Scotophihus leucogaster (e)

curved with an initial FM sweep that ends with a QCF sweep (Fig. 1e).

\section{Quantitative analysis}

\section{Discriminant function analysis}

Four discriminant functions were produced. The first discriminant function accounted for $58.2 \%$ of the total variation between bat species and the second $40.3 \%$ (Table 2). Only the first two functions were important because they accounted for $98.5 \%$ of the total variation. The first function has canonical correlation of 0.916 (Table 3).

The four canonical discriminant functions obtained for the species groups gave a combined $\chi^{2}(28)=$ 205.604, $p<0.05$ (Table 4). It indicated that the function as a whole is significant and the discriminant function does better than chance at separating the bat calls into species groups. After removal of the first function, there was still a strong association between bat species and predictors, $X^{2}(18)=97.084, p<0.05$ (Table 4). After removal of the second function, $\chi^{2}$ $(10)=7.572, p=0.671$, there was no longer a strong association between bat species and predictors (Table 3). The first function (Wilks' lambda $=0.31$ ) has the greatest discriminatory ability in classifying calls in different species groups (Table 4).
Overall, $69.7 \%$ of the echolocation calls were correctly classified into the different species of bats, exceeding the value for classification based on chance (33.3\%) (Table 5). At the individual group level, $52.6 \%$ of calls of Scotophilus dinganii were correctly classified, $75.5 \%$ of Scotophilus leucogaster, $70.0 \%$ of Mops niveiventer, $55.6 \%$ of Mops condylurus, and $93.8 \%$ of Chaerephon major (Table 5).

About $47.4 \%$ of calls of Scotophilus dinganii were misclassified as calls of S. leucogaster while $25.0 \%$ of calls of Scotophilus leucogaster were misclassified as belonging to Scotophilus dinganii. For Mops niveiventer, $30.0 \%$ of their calls were misclassified as belonging to Mops condylurus. For Chaerephon major, 6.3\% of their calls were classified as belonging to Scotophilus dinganii (Table 5).

The plot of mean canonical scores and the canonical discriminant functions (Fig. 2) demonstrates that the species are well separated in multidimensional space. It can be observed that function 1 mostly separate the calls from Mops condylurus and Mops niveiventer which are two closely related species from those of Scotophilus dinganii and Scotophilus leucogaster which are also closely related. Then, function 2 mostly separates Mops species and Scotophilus species from Chaerephon major. 
Table 3 Relative power of discriminant functions. The first two functions are the most important and account for about 98.5\% of the total variation

\begin{tabular}{lllll}
\hline Function & $\begin{array}{l}\text { Eigen } \\
\text { value }\end{array}$ & \% of variance & Cumulative \% & $\begin{array}{l}\text { Canonical } \\
\text { correlation }\end{array}$ \\
\hline 1 & 5.216 & 58.2 & 58.2 & 0.916 \\
2 & 3.615 & 40.3 & 98.5 & 0.885 \\
3 & 0.098 & 1.1 & 99.6 & 0.298 \\
4 & 0.036 & 0.4 & 100.0 & 0.186 \\
\hline
\end{tabular}

First four canonical discriminant functions were used in the analysis

\section{Discussion}

The Anabat frequency division bat detector is one of a number of ultrasonic devices used to detect and identify bat species based on the identity of their echolocation calls. Although acoustic detectors permit the sampling of bats in a larger area than traps or nets, species with low-intensity vocalization may not adequately be represented because echolocation calls of low intensity weaken rapidly in the atmosphere as such cannot be detected from afar (O’Farrell \& Gannon, 1999). Moreover, before acoustic detection can be used in an area to identify bats, reference collections of bat echolocation calls need to be established. The use of the Anabat ultrasound detector to record echolocation calls of bats in the Sahelian region represents a start toward establishing a comprehensive library of reference echolocation calls of bats in Cameroon.

In our study, we recorded echolocation calls of most abundant insectivorous bats present in the sahelian region of Far North Cameroon (Mops condylurus, Chaerephon major, Mops niveiventer, Scotophilus dinganii, and Scotophilus leucogaster) (Bol et al., 2011), using an Anabat ultrasound detector after they were hand-release. We later performed a discriminant function analysis (DFA) to classify echolocation calls into five species groups. The echolocation calls were correctly classified to species with $69.7 \%$ accuracy using cross validation DFA. The sonograms were also viewed and revealed differences in call structure among the different species. Overall, the level of accurate classification of calls into species group by DFA was reasonably high. However, classification rates at species level were comparatively lower when compared to similar studies

Table 4 Wilks' lambda table shows that the first two functions have the highest discriminatory ability in classifying calls into species group

\begin{tabular}{lllll}
\hline Test of function(s) & Wilks' lambda & Chi-square & Df & Sig. \\
\hline 1 through 4 & 0.031 & 205.604 & 28 & 0.000 \\
2 through 4 & 0.191 & 97.804 & 18 & 0.000 \\
3 through 4 & 0.880 & 7.572 & 10 & 0.671 \\
4 & 0.966 & 2.069 & 4 & 0.723 \\
\hline
\end{tabular}

(Hughes et al., 2011; Kofoky et al., 2009; Rodríguez-San Pedro \& Simonetti, 2013). The relative poor performance of the DFA may be attributed to the use of fewer individual of each species. It can also be attributed to the fact that handling and release of bats affect their call structure. Artificial neural networks (Parsons, 2001) and synergetic recognition algorithms (Obrist, Boesch, \& Flückiger, 2004) are two other methods that can be applied for acoustic identification of species. Although ANNs could perform better than DFA, they are not trivial to use (Parsons \& Jones, 2000). They are the most computationally intensive techniques and take the longest amount of time to train (Armitage \& Ober, 2010). Synergetic algorithms require highly sophisticated software and large storage memory (Obrist et al., 2004). Because the ultimate aim of this study was to devise an objective identification tool to be used by other researchers in the region, a standard statistical approach such as the quadratic DFA remains the preferred method, as it is relatively simple and easily accessible.

The three genera clearly differed from each other in multivariate space. Figure 2 shows that the groups centroids of Scotophilus dinganii (forearm length 49-57 $\mathrm{mm}$ ) and Scotophilus leucogaster (forearm 43-51 $\mathrm{mm}$ ) are almost on the same spot, indicating that call parameters of these morphologically similar species are almost the same. Their calls differ from the calls of Mops condylurus (forearm 45-50 mm) and Mops niveiventer (forearm 44-47 $\mathrm{mm}$ ), which are species that are smaller than the Scotophilus species but are morphologically similar to each other. The calls of Chaerephon major (forearm 42-44 mm) are distinct from the Scotophilus species and the Mops species. This confirms that closely related species, with similar morphology and/or ecology may show convergent evolution of their call features and hence similarities in their echolocation calls (Papadatou, Butlin, \& Altringham, 2008; Parsons \& Jones, 2000).

To the best of our knowledge, echolocation calls for Mops niveiventer, Chaerephon major, and Scotophilus leucogaster presented here are the first published records of these species using the Anabat detector in Africa. Mops condylurus and Scotophilus dinganii have been studied in other parts of Africa using the Anabat and their echolocation call parameters published. The two Scotophilus species in this study emitted typical broadband, curved FM/QCF calls with an initial steep FM sweep that ends with a QCF. All FM/QCF bats are expected to forage mainly in open spaces (Vaughan et al., 1997) because FM/QCF calls are suitable for use in open environments with some obstacles (Simmons, Fenton, \& O'Farrell, 1979). Scotophilus dinganii recorded calls with a maximum frequency of $58.5 \pm 8.9 \mathrm{kHz}$, minimum frequency of $52.6 \pm 6.2 \mathrm{kHz}$, frequency at the knee of 
Table 5 Classification table showing the percentage of calls correctly classified into species groups

\begin{tabular}{lllllll}
\hline \multicolumn{1}{c}{ Species } & \multicolumn{2}{l}{ Predicted group membership } & & Total \\
\cline { 2 - 7 } & S. dinganii & S. leucogaster & M. niveiventer & M. condylurus & C. major \\
\hline S. dinganii & 52.6 & 47.4 & 0.0 & 0.0 & 0.0 & 100.0 \\
S. leucogaster & 25.0 & 75.0 & 0.0 & 0.0 & 0.0 & 100.0 \\
M. niveiventer & 0.0 & 0.0 & 70.0 & 30.0 & 0.0 & 100.0 \\
M. condylurus & 0.0 & 11.1 & 33.3 & 55.6 & 0.0 & 100.0 \\
C. major & 6.2 & 0.0 & 0.0 & 0.0 & 93.8 & 100.0 \\
\hline
\end{tabular}

$69.7 \%$ of original grouped cases correctly classified

$58.5 \pm 8.9 \mathrm{kHz}$, and characteristic frequency of $52.7 \pm$ $6.2 \mathrm{kHz}$ (Table 1). These frequency parameters were generally higher than those recorded by Jacobs, Barclay, and Walker (2007) in Kwazulu-Natal; Schoeman and Waddington (2011) in Durban; Taylor, Sowler, Schoeman, and Monadjem (2013) and Linden et al. (2014) in Soutpansberg; and Taylor et al. (2013) at Farm Welgevonden in South Africa. Sonograms of all molossids bats indicate that their echolocation calls are broadband FM calls (Table 2). This implies that many of them are expected to forage in the open or at the edge of forests, using shorter duration broadband signals that are well suited for three-dimensional target localization and for separating figures and ground (Simmons, 1973). Mops condylurus recorded calls with Fmax of $39.2 \pm 6.9 \mathrm{kHz}$, Fmin of $34.2 \pm 6.7 \mathrm{kHz}, \mathrm{Fk}$ of $38.2 \pm 7.3 \mathrm{kHz}$, and Fc of $38.67 \pm 7.3 \mathrm{kHz}$ (Table 2). These frequency parameters were generally higher than those recorded by Linden et al. (2014); Monadjem, Taylor, Cotterill, and Schoeman (2010); Naidoo, Mackey, and Schoeman
(2011); Schoeman and Waddington (2011); and Taylor et al. (2013) in Republic of South Africa and Taylor et al. (2013) in Swaziland. These results suggest a geographical variation in echolocation calls of these two species. Similar geographic variation in calls were reported for other species by Thomas, Bell, and Fenton (1987). This variation can be attributed to differences in techniques of recording and analyzing calls, notably the hand-release method used during the study as opposed to recordings made in a flight tent or in an open space. It might also be due to the habitat differences (clutter or open) or the distance from the detector and humidity of air (Kalko \& Schnitzler, 1993). Intraspecific variation of echolocation calls can also be caused by differences in sex (Jones, Gordon, \& Nightingale, 1992) and age (Masters, Raver, \& Kazial, 1995).

\section{Conclusions}

Despite the fact that our study was based on a limited sample sizes $(N \leq 20$ for all species $)$, the study

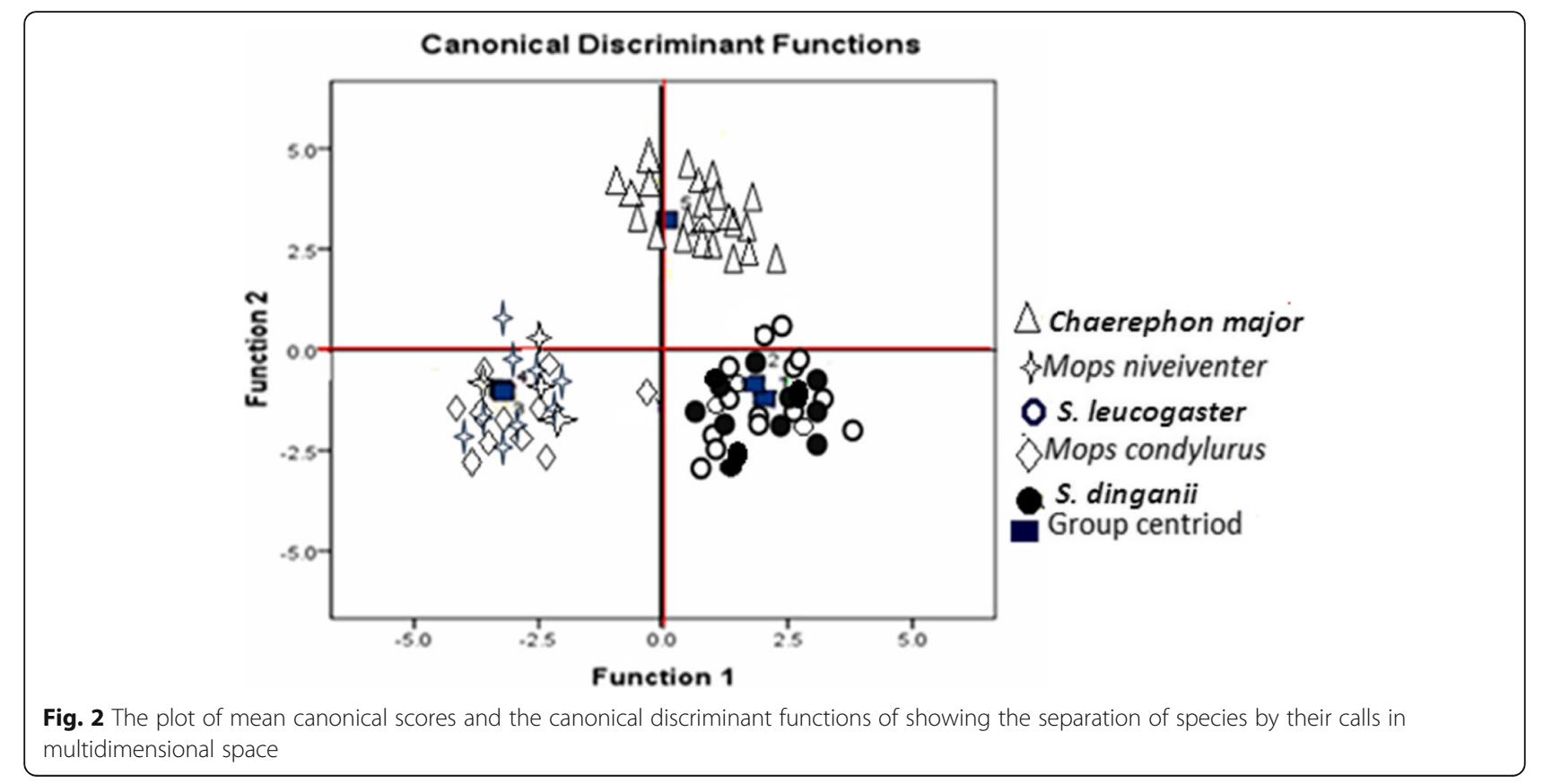


demonstrates that a quantitative method (DFA) could potentially provide an effective technique to acoustically sample bats in the region, but before this can be practical the echolocation calls of these five species need to be recorded in different habitat types such as clustered and open spaces in order to take into account geographical variation of echolocation calls. The study also provides evidence that acoustic techniques can play a significant role in complementing traditional capture techniques.

\section{Abbreviations}

ANN: Artificial neural network; DFA: Discriminant function analysis; Dur: Duration; Fc: Characteristic frequency; Fk: Frequency at the knee; FM: Frequency modulation; Fmax: Maximum frequency; Fmean: Mean frequency; Fmin: Minimum frequency; GPS: Global Positioning System; MANOVA: Multivariate analysis of variance; QCF : Quasi constant frequency; Sc: Characteristic slope; Si: Initial slope; Tc: Time at characteristic frequency; Tk: Time at knee; $x^{2}$ : Chi-square

\section{Acknowledgements}

Special thanks go to Bol A Anong Alima and Mmae Jacques Patrick for their assistance in the fieldwork.

\section{Availability of data and materials}

Data sharing is not applicable to this article because datasets were generated or analyzed during the current study.

\section{Authors' contributions}

BFEM, AMM, DET, and TJL designed and performed this work. All authors read and approved the final manuscript.

\section{Ethics approval and consent to participate}

The authors declare that this work was carried out within an appropriate ethical framework.

\section{Competing interests}

The authors declare that they have no competing interests.

\section{Publisher's Note}

Springer Nature remains neutral with regard to jurisdictional claims in published maps and institutional affiliations.

\section{Author details}

'Department of Biological Sciences, Faculty of Sciences, University of Maroua, Maroua, Cameroon. ${ }^{2}$ Département des Sciences Biologiques, Ecole Normale Supérieure, Université de Yaoundé I, Yaounde, Cameroon.

Received: 20 February 2018 Accepted: 9 May 2018

Published online: 25 May 2018

\section{References}

Armitage, D. W., \& Ober, H. K. (2010). A comparison of supervised learning techniques in the classification of bat. Ecological Informatics, 5, 465-473.

Bakwo Fils E. M. (2009). La communauté de chauves-souris de la réserve de biosphère du Dja, Cameroun, Canopée, 28, 6-8.

Bakwo Fils, E. M. (2010a). Inventaire des chauves-souris de la réserve de biosphère du Dja, Cameroun. Le Véspère, 2, 11-20.

Bakwo Fils, E. M. (2010b). The bats of Cameroon: Proving the benefits of forgotten fruit bats. Bats, 28(2), 11-13.

Bakwo Fils, E. M. (2014). Voucher specimen details for Bakwo Fils et al. 2014, (p. 35. 4). African Bats Conservation News. https://www.africanbats.org/Documents/ ABCN/ABCN_36.pdf.

Bakwo Fils, E. M., Bol, A., \& Tchuenguem Fohouo, F.-N. (2012). The first record of the Giant House Bat Scotophilus nigrita (Schreber, 1774) in Cameroon (Mammalia: Chiroptera). Biodiversity Journal, 3(1), 55-58.

Bakwo Fils, E. M., Bol, A. G., Tsala, B. D., Guieké, B. B., David Emery, T., \& Fotso, A. K. (2014). Diversity of bats of the Far North Region of Cameroon-with two first records for the country. Biodiversity, 15(1), 16-22.
Betts, B. J. (1998). Effects of inter individual variation in echolocation calls on identification of big brown and silver-haired bats. Journal of Wildlife Management, 62(3), 1003-1010.

Bol A Anong A. G., Guieké, B. B., \& Tsala, B. D. (2011). Introduction à I inventaire des Chauves-souris (Chiroptères) de la ville de Maroua, Extrême-Nord Cameroun, mémoire de DIPES II, ENS de Maroua, p. 95

Bourtrais, J., Beauvilain, A., Gubry, P., Barreteau, D., Dieu, M., Breton, R., ... Frechou, H. (1984). Le Nord du Cameroun: des hommes, une région. In Edition de l'office de la recherche scientifique et technique Outre-mer, (p. 551). Paris: ORSTOM.

Britzke, E. R., Murray, K. L., Heywood, J. S., \& Robbins, L. W. (2002). Acoustic identification. In A. Kurta, \& J. Kennedy (Eds.), The Indiana bat: Biology and management of an endangered species, (pp. 220-224). Austin: Bat Conservation International.

Cosson, J. F. (1995). Captures of Myonycteris torquata (Chiroptera: Pteropodidae) in forest canopy in South Cameroon. Biotropica, 27(3), 395-396.

Digby, P. G. N.. \& Kempton, R. A. (1987). Multivariate analysis of ecological communities, (p. 217). London: Chapman and Hall.

Hassanin, A. (2014). Description of a new bat species of the tribe Scotonycterini (Chiroptera, Pteropodidae) from Southwestern Cameroon. Comptes Rendus Biologies, 337(2), 134-142

Hayman, R. W., \& Hill, J. E. (1971). Order Chiroptera. In J. Meester, \& H. W. Setzer (Eds.), The mammals of Africa. An identification manual. Part 2, (p. 73). Washington, D.C.: Smithsonian Institution Press.

Hughes, A. C., Satasook, C., Bates, P. J., Soisook, P., Sritongchuay, T., Jones, G., \& Bumrungsri, S. (2011). Using echolocation calls to identify Thai bat species: Vespertilionidae, Emballonuridae, Nycteridae and Megadermatidae. Acta Chiropterologica, 13(2), 447-455.

Hutson, A. M., Mickleburgh, S. P., \& Racey, P. A. (2001). Microchiropteran bats: Global status survey and conservation action plan, IUCN/SSC Chiroptera specialist group (). Gland and Cambridge: IUCN.

Jacobs, D. S., Barclay, R. M. R., \& Walker, M. H. (2007). The allometery of echolocation call frequencies of insectivorous bats: Why do some species deviate from the pattern? Oecologia, 152, 583-594.

Jones, G., Gordon, T., \& Nightingale, J. (1992). Sex and age differences in the echolocation calls of the lesser horseshoe bat, Rhinolophus hipposideros. Mammalia, 56(2), 189-193.

Jones, G., Jacobs, D. S., Kunz, T. H., Willig, M. R., \& Racey, P. A. (2009). Carpe noctem: The importance of bats as bioindicators. Endangered Species Research, 8, 93-115.

Kalka, M. B., Smith, A. R., \& Kalko, E. K. V. (2008). Bats limit arthropods and herbivory in a tropical forest. Science, 320, 71 .

Kalko, E. K. V., \& Schnitzler, H. U. (1993). Plasticity in echolocation signals of European pipistrelle bats in search flight: Implications for habitat use and prey detection. Behavioral Ecology and Sociobiology, 33(6), 415-428.

Kingston, T., Francis, C. M., Akbar, Z., \& Kunz, T. H. (2003). Species richness in an insectivorous bat assemblage from Malaysia. Journal of Tropical Ecology, 19, 1-12

Kofoky, A. F., Randrianandrianina, F., Russ, J., Raharinantenaina, I., Cardiff, S. G., Jenkins, R. K. B., \& Racey, P. A. (2009). Forest bats of Madagascar: Results of acoustic surveys. Acta Chiropterologica, 11(2), 375-392.

Krusic, R. A., Yamasaki, M., Neefus, C. D., \& Pekins, P. J. (1996). Bat habitat use in the White Mountain National Forest. Journal of Wildlife Management, 60, 625-631.

Kuenzi, A. J., \& Morrison, M. L. (1998). Detection of bats by mist-nets and ultrasonic sensors. Wildlife Society Bulletin, 26, 307-311.

Kunz, T. H., Torrez, E. B., Bauer, D., Lobova, T., \& Fleming, T. H. (2011). Ecosystem services provided by bats. Annals of the New York Academy of Sciences, 1223, 1-38.

Law, B. S., Anderson, J., \& Chidel, M. (1999). Bat communities in a fragmented landscape on the south-west slopes of New South Wales, Australia. Biological Conservation, 88, 333-345.

Lebreton, M., Bakwo Fils, E. M., Takuo, J. M., \& Diffo, J. L. D. (2014). The first record of the african sheath-tailed bat Coleura afra (peters, 1852) (Mammalia, Chiroptera) in, Cameroon with information on its ecology. African Bats Conservation News, 36, 2-4.

Linden, V. M. G., Weier, S. M., Gaigher, I., Kuipers, H. J., Weterings, M. J. A., \& Taylor, P. J. (2014). Changes of bat activity, species richness, diversity and community composition over an altitudinal gradient in the Soutpansberg range, South Africa. Acta Chiropterologica, 16(1), 27-40. https://doi.org/10. 3161/150811014X683246

Lobova, T. A., Geiselman, C. K., \& Mori, S. A. (2009). Seed dispersal by bats in the Neotropics. New York: New York Botanical Garden Press.

Masters, W. M., Raver, K. A. S., \& Kazial, K. A. (1995). Sonar signals of big brown bats, Eptesicus fuscus, contain information about individual identity, age, and family affiliation. Animal Behaviour, 50, 1243-1260. 
Medellin, R. A., Equihua, M., \& Amin, M. A. (2000). Bat diversity and abundance as indicators of disturbance in a Neotropical rainforest. Conservation Biology, 14, $1666-1675$

Mickleburgh, S. P., Hutson, A. M., \& Racey, P. A. (1992). Old world fruit bats, an action plan for their conservation. Gland: International Union for the Conservation of Nature and Natural Resources.

Monadjem, A., Taylor, P. J., Cotterill, F. P. D., \& Schoeman, M. C. (2010). Bats of southern and Central Africa. A biogeographic and taxonomic synthesis, (p. 596). Johannesburg: Wits University Press.

Murray, K. L., Britzke, E. R., Hadley, B. M., \& Robbins, L. W. (1999). Surveying bat communities: A comparison between mist nets and the Anabat II bat detector system. Acta Chiropterologica, 1, 105-112.

Naidoo, S., Mackey, R. L., \& Schoeman, M. C. (2011). Foraging ecology of insectivorous bats (Chiroptera) at a polluted and an unpolluted river in an urban landscape. Durban Museum Novitates, 34, 21-28.

O'Farrell, M. J. (1997). Use of echolocation calls for the identification of free-flying bats. Transactions of the Western Section of the Wildlife Society, 33, 1-8.

O'Farrell, M. J., \& Gannon, W. L. (1999). A comparison of acoustic versus capture techniques for the inventory of bats. Journal of Mammalogy, 80, 24-30.

O'Farrell, M. J., \& Miller, B. W. (1999). Use of vocal signatures for inventory of freeflying Neotropical bats. Biotropica, 31, 507-516.

O'Farrell, M. J., Miller, B. W., \& Gannon, W. L. (1999). Qualitative identification of free-flying bats using the Anabat detector. Journal of Mammalogy, 80, 11-23.

Obrist, M. K., Boesch, R., \& Flückiger, P. F. (2004). Variability in echolocation call design of 26 Swiss bat species: Consequences, limits, and options for automated field identification with a synergetic pattern recognition approach. Mammalia, 68, 307-322.

Ochoa, G. J., O'Farrell, M. J., \& Miller, B. W. (2000). Contribution of acoustic methods to the study of insectivorous bat diversity in protected areas from northern Venezuela. Acta Chiropterologica, 2(2), 171-183.

Ochoa, J. (2000). Efectos de la extracción de maderas sobre la diversidad de mamiferos pequenos en bosques de tierras bajas de la Guayana Venezolana. Biotropica, 32, 146-164.

Papadatou, E., Butlin, R. K., \& Altringham, J. D. (2008). Identification of bat species in Greece from their echolocation calls. Acta Chiropterologica, 10(1), 127-143.

Parsons, S. (2001). Identification of New Zealand bats (Chalinolobus tuberculatus and Mystacina tuberculata) in flight from analysis of echolocation calls by artificial neural networks. Journal of zoology London, 253, 447-456.

Parsons, S., \& Jones, G. (2000). Acoustic identification of twelve species of echolocating bat by discriminant function analysis and artificial neural networks. Journal of Experimental Biology, 203, 2641-2656.

Racey, P. A. (1998). Ecology of European bats in relation to their conservation. In T. H. Kunz, \& P. A. Racey (Eds.), Bat biology and conservation, (pp. 249-260). Washington, D.C.: Smithsonian Institution Press.

Robbins, C. B., De Vree, F., \& Van Cakenberghe, V. (1985). A systematic revision of the African bat genus Scotophilus (Vespertilionidae). Annalen van het Koninklijk Museum voor Midden Afrika: Zoologische Wetenschappen, 246, 51-84.

Rodríguez-San Pedro, A., \& Simonetti, J. A. (2013). Acoustic identification of four species of bats (Order Chiroptera) in central Chile. Bioacoustics. https://doi.org/10.1080/09524622.2013.763384.

Rosevear, D. R. (1965). The bats of West Africa, (p. xvii + 418). London: Trustees of the British Museum (Nat. Hist.).

Russo, D., \& Jones, G. (2002). Identification of twenty-two bat species (Mammalia: Chiroptera) from Italy by analysis of time-expanded recordings of echolocation calls. Journal of Zoology, 258, 91-103.

Schipper, J., Chanson, J. S., Chiozza, F., Cox, N. A., Hoffmann, M., et al. (2008). The status of the World's land and marine mammals: Diversity, threat, and knowledge. Science, 322, 225-230.

Schoeman, M. C., \& Waddington, K. J. (2011). Do deterministic processes influence the phenotypic patterns of animalivorous bat ensembles at urban rivers? African Zoology, 46(2), 288-301.

Sedlàcek, O. D., Horak, J., Riegert, J., Reif, J., \& Horàcek, I. (2006). Comments on Welwitsch's mouse-eared bat (Myotis welwitschii) with the first record from Cameroon. Mammalia Biology, 71(2), 120-123.

Simmons, J. A. (1973). The resolution of target range by echolocating bats. Journal of the Acoustical Society of America, 54(1), 157-173.

Simmons, J. A., Fenton, M. B., \& O'Farrell, M. J. (1979). Echolocation and pursuit of prey by bats. Science, 203, 16-21.

Taylor, P. J., Sowler, S., Schoeman, M. C., \& Monadjem, A. (2013). Diversity of bats in the Soutpansberg and Blouberg Mountains of northern South Africa:
Complementarity of acoustic and non-acoustic survey methods. South African Journal of Wildlife Research, 43(1), 12-26.

Thomas, D. W., Bell, G. P., \& Fenton, M. B. (1987). Variation in echolocation call frequencies recorded from north American vespertilionid bats: A cautionary note. Journal of Mammalogy, 68, 842-847.

Vaughan, N., Jones, G., \& Harris, S. (1997). Identification of British bat species by multivariate analysis of echolocation call parameters. Bioacoustics, 7, 189-207.

Willig, M. R., Kaufman, D. M., \& Stevens, R. D. (2003). Latitudinal gradient of biodiversity pattern: process, scale and synthesis. Annual Review of Ecology and Systematics, 34, 273-309.

Yengue, J. L., \& Callot, Y. (2002). L'arbre et la ville dans la région de Maroua (Extrême-Nord-Cameroun). Sciences et Changements Planétaires / Sécheresse, 13(3), 155-163.

\section{Submit your manuscript to a SpringerOpen ${ }^{\circ}$ journal and benefit from:}

- Convenient online submission

- Rigorous peer review

- Open access: articles freely available online

- High visibility within the field

- Retaining the copyright to your article

Submit your next manuscript at $>$ springeropen.com 